\title{
Co-seismic surface deformation of the 2011 off the Pacific coast of Tohoku Earthquake: Spatio-temporal EOF analysis of GPS data
}

\author{
Emmy T. Y. Chang ${ }^{1}$ and Benjamin F. Chao ${ }^{2}$ \\ ${ }^{1}$ Institute of Oceanography, National Taiwan University, Taipei, Taiwan \\ ${ }^{2}$ Institute of Earth Sciences, Academia Sinica, Taipei, Taiwan
}

(Received April 19, 2011; Revised July 3, 2011; Accepted July 4, 2011; Online published September 27, 2011)

\begin{abstract}
On March 11, 2011, Japan's Pacific coast of Tohoku (northeast Honshu) was hit by a strong tsunami set off by a large off-shore magnitude 9.0 earthquake. We employ the method of empirical orthogonal function (EOF) analysis on the dense, continuous GPS data from Japan's GEONET to obtain and examine in detail the spatiotemporal behavior of the 3-D co-seismic and near co-seismic surface deformation of Japan's island of Honshu. For northern Honshu, where the dominant deformation occurred, the co-seismic horizontal displacement and the post-seismic relaxation were toward the east-southeast with a maximum amplitude of nearly 4 meters. The vertical component experienced a subsidence of up to $50 \mathrm{~cm}$ on the east side of Honshu toward the epicenter but with a slight uplift to the west. The EOF solutions also detect clear post-seismic relaxation on the $\sim 20 \mathrm{~cm}$ level, of essentially the same deformation pattern but with a larger extent during the hours to days after the mainshock, as well as (3-D) signals from some of the major foreshocks/aftershocks. The co-seismic horizontal strain field derived from the EOF solutions exhibits an interesting spatial pattern that provides further insight towards better understanding of the dynamic and complex seismotectonics of the region.
\end{abstract}

Key words: EOF, GEONET, co-seismic displacement, post-seismic relaxation, strain field.

\section{Introduction}

On March 11, 2011, Japan's Pacific coast of Tohoku (northeast Honshu) was hit by a strong tsunami set off by a large off-shore magnitude 9.0 earthquake. The epicentral region is where four tectonic plates converge, the detail of which has been the subject of much consideration with models differing in the proposed plate boundaries and their interactions (e.g., DeMets, 1992; Seno et al., 1993, 1996; Bird, 2003), especially with regard to the precise location of the boundaries around central Honshu Island (Seno et al., 1996). However, the models agree that the Pacific Plate subducts beneath central northern Honshu and Hokkaido Island along the Japan-Kuril Trench, and the Philippine Sea Plate subducts obliquely beneath southern Honshu and Shikoku Island along the Nankai Trough (Seno and Takano, 1989) (Fig. 1). The 2011 Tohoku earthquake was a reversethrusting earthquake with an EW compression subject to the Pacific Plate subducting under the Okhotsk Plate along the NE-SW trending subduction zone. Northern Honshu has seen relatively less seismicity historically compared with southern Honshu where large earthquakes have occurred on record approximately every 125 years since 1498 (e.g. Ando, 1975).

Two foreshocks of magnitude 7.3 and 6.0 took place 2 days earlier within $100 \mathrm{~km}$ north of the $M 9.0$ mainshock with similar focal mechanisms, and many major aftershocks

Copyright (c) The Society of Geomagnetism and Earth, Planetary and Space Sciences (SGEPSS); The Seismological Society of Japan; The Volcanological Society of Japan; The Geodetic Society of Japan; The Japanese Society for Planetary Sciences; TERRAPUB.

doi:10.5047/eps.2011.07.002 occurred in the following days in an area of persistent background seismicity extending several hundred kilometers. Figure 1 lists 15 major events (labeled in time order; the mainshock is event \#3) of the sequence with magnitude $>6.0$ that occurred up until March 15, as reported by rapid determination from Global Centroid Moment Tensor (GCMT) solutions (website://www.globalcmt.org) and the USGS/NEIC source location. The yellow stars in Fig. 1 (and the violet circles in subsequent plots) indicate the GCMT epicenters of these events among the many minor aftershocks indicated as violet dots.

Japan has deployed GEONET, a nationwide, dense, continuous GPS network, since 1993 (Sagiya, 2004), the observations of which have been used to study tectonic motions in Japan (e.g., Sagiya et al., 2000; Aoki and Scholz, 2003). GEONET now consists of over 1000 GPS stations covering the entire Japanese islands with an average spacing of $25 \mathrm{~km}$. In this paper, we employ the method of empirical orthogonal function (EOF) analysis (e.g. Preisendorfer, 1988; Jolliffe, 2002) on the short-term GEONET GPS data to extract systematic spatio-temporal signals and to examine the behavior of the co-seismic and near co-seismic surface deformation in Japan (on-land) due to this earthquake.

\section{Data Processing and EOF Space-Time Analysis}

The complete data set used in this study is from the ARIA team at JPL (ftp://sideshow.jpl.nasa.gov/pub/usrs/ARIA/). The position values are solved by means of the kinematic precise-point-positioning method using JPL's GIPSYOASIS software, including a single-station bias-fixing algorithm and JPL's orbit and clock products. Each time se- 


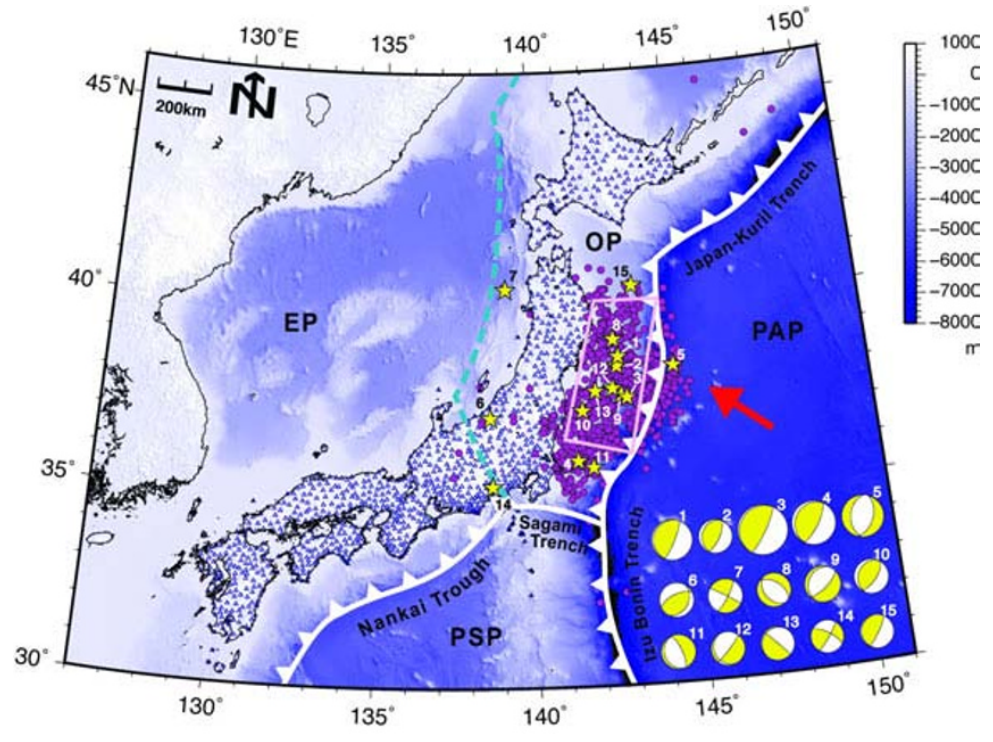

Fig. 1. Plate tectonic setting around Japan (EP: Eurasian Plate; OP: Okhotsk Plate; PAP: Pacific Plate; PSP: Philippine Sea Plate). The yellow stars indicate the epicenters of 15 major events (labeled in time order) of the earthquake sequence with a source mechanism determined by the GCMT solution, among the many smaller aftershocks indicated as violet dots.

ries represents one of the 3 components (east, north, up) of the position vector of one GPS station with respect to the ITRF reference frame. In this study, we use the 30min interval time series spanning March 1-15 (1249 available GPS stations) for a synoptic solution of the surface displacement field caused by the earthquake sequence, as well as sub-segments spanning March 7-10 (1157 stations) for the pre-seismic, and March 11-15 (1064 stations) for the post-seismic periods. In addition, we also use the 5-min interval data for the day of March 11 (1152 stations) for computing the co-seismic strain field.

We first "clean" the time series as follows before feeding them to the EOF analysis. First, we screen out a small number of erratic stations and de-glitch from the data obvious outlier points, as deemed appropriate. We then leastsquares fit the time series with a linear combination of a mean, 9 major tidal sinusoidal signals $\left(\mathrm{K}_{2}, \mathrm{~S}_{2}, \mathrm{M}_{2}, \mathrm{~N}_{2}, 2 \mathrm{~N}_{2}\right.$, $\mathrm{K}_{1}, \mathrm{P}_{1}, \mathrm{O}_{1}, \mathrm{Q}_{1}$ ), plus a Heaviside step-function at the origin time of the $M 9.0$ mainshock. The sinusoidal terms are to account for ocean tidal loading effects and any day-night weather-related effect at each station (the solid tides had already been corrected out beforehand), and their estimation by a least-squares fit here is simply meant to be used to remove these signals, as best one can. We achieve the latter by subtracting out the fitted sinusoids from the time series along with the mean but retaining the earthquakeinduced step-function "jump" term. The unmodeled residuals should now be random noises but in actuality still often contain the so-called common mode errors (CME), especially in the vertical component (Williams et al., 2004; Dong et al., 2006). CME are spatially quasi-unison motions of unknown origin often found in multi-station continuous GPS data; they are often readily separated out by EOF (see below).

We take all the treated time series and construct an $n \times$ $m$ space-time data matrix $D$, for all $m$ stations during the specified time span of $n$ time steps, for each of the 3 com- ponents. The method of EOF, also known as the principal component analysis, decomposes $D$ (in our case using singular-value decomposition) into a linear combination of orthogonal standing oscillations

$$
D(x, t)=\Sigma S_{i}(x) T_{i}(t),
$$

where $S_{i}(x) T_{i}(t)$ is the $i$ th EOF "mode" formed by the multiplication of a spatial pattern $S_{i}(x)$ with a time series $T_{i}(t)$ (the two functions will always be presented in pairs). Here we choose the scaling so as to normalize the $S_{i}(x)$ with respect to its maximum value, thus concentrating the magnitude information into $T_{i}(t)$ which thus has the same unit as the data, namely $\mathrm{cm}$. The polarity is chosen so that the co-seismic jump is positive with time. The corresponding eigenvalue that is simultaneously obtained in the decomposition solution gives the percentage variance explained by the given mode. In our present case, almost all seismic signals are captured in one single leading mode, which is then to be interpreted in terms of physical processes.

\section{Results for the Spatio-Temporal Behavior \\ 3.1 Synoptic deformation of March 1-15}

Figure 2 shows the leading EOF mode of the 3-D surface deformation solved using the 30-min (treated) data series for the half-month period of March 1-15, straddling the foreshocks, the $M 9.0$ mainshock, and the major aftershocks during the period (Fig. 1), the timing of which is indicated by the vertical lines in the EOF time series in Fig. 2. Evident from the time series, the co-seismic displacement caused by the mainshock, not surprisingly, is by far the dominant signal captured in this EOF mode with a percentage variance as high as $98-99 \%$ for the horizontal and $32 \%$ for the vertical. The foreshocks and aftershocks, with epicenters a fair distance off-shore, show relatively minor signals in comparison (but see below).

The spatial patterns of the EOF mode are shown in the maps of Fig. 2. The east-component sees a co-seismic east- 
East

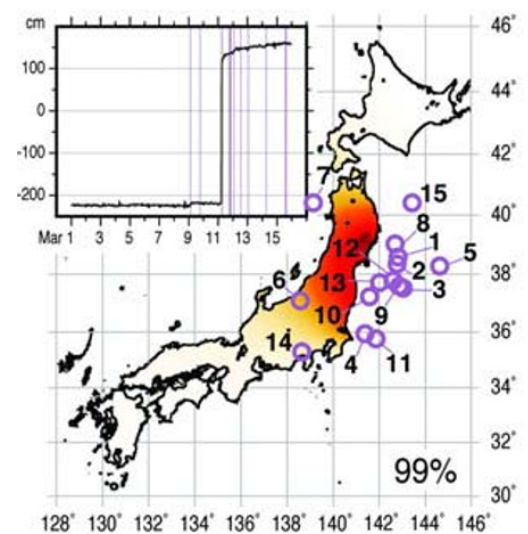

North

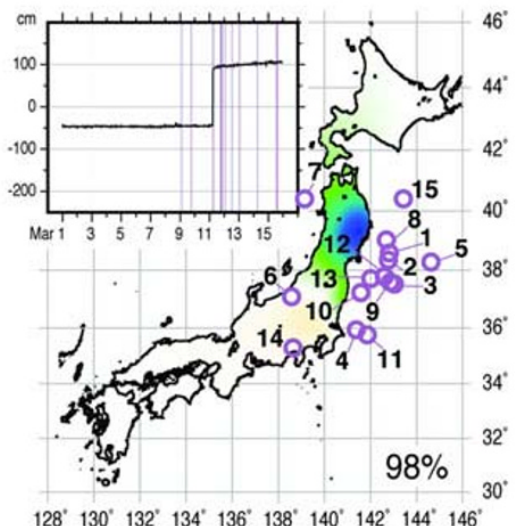

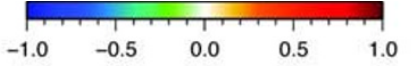

Up

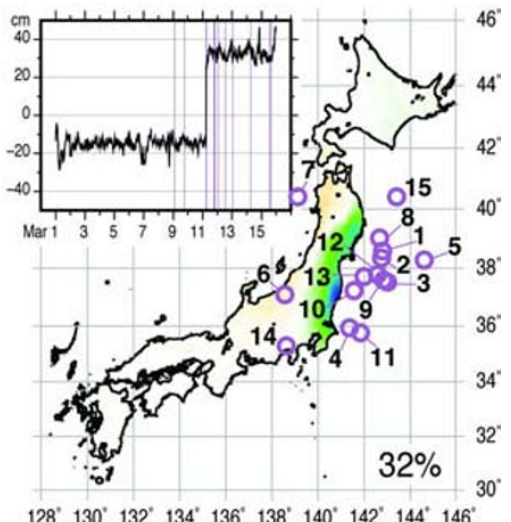

Fig. 2. The leading EOF mode of the 3-D surface deformation (east-, north- and up-component) solved using the 30-min GEONET GPS data for the period March 1-15, showing the synoptic behavior of the spatial pattern and the corresponding time series with the percentage variance. The violet lines in the time series indicate the origin times of foreshocks, the $M 9.0$ mainshock, and the major aftershocks during the period.

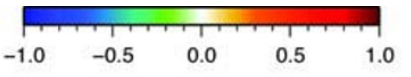

\section{East}

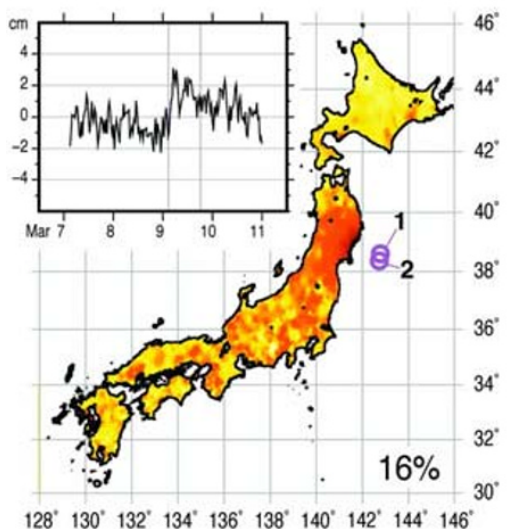

North

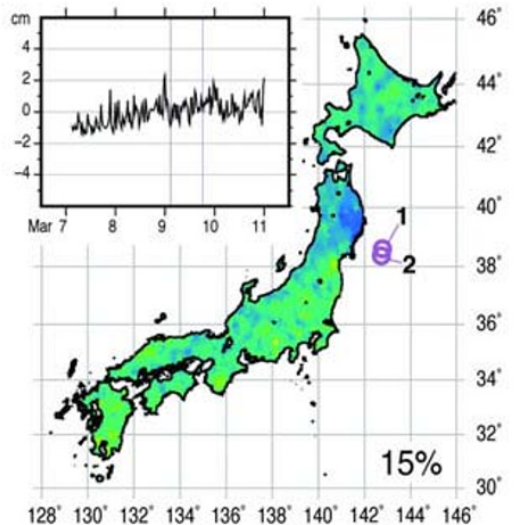

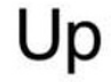

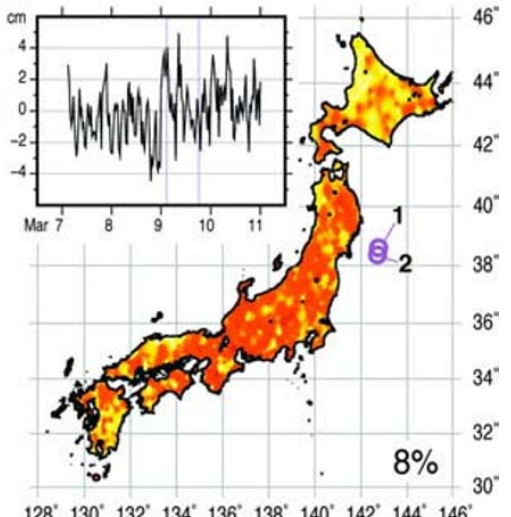

Fig. 3. Same as Fig. 2, but for EOF solutions for the pre-seismic/foreshock period of 4 days (March 7-10) prior to the mainshock. The origin times of events \#1 and \#2 are also plotted.

ward displacement of maximum $350 \mathrm{~cm}$. The corresponding north-component sees a co-seismic southward displacement of maximum $145 \mathrm{~cm}$. The combined horizontal east southeast displacement field prevails over northern Honshu, with the strongest motion concentrated on the eastern shore toward the epicenter as expected. Southern Honshu sees much weaker, cm-level horizontal motion, but in a northeast direction obliquely converging to northern Honshu.

The vertical component, despite its relatively-poorer determination in GPS observations and the presence of higher non-seismic signals, shows a different behavior: While the western side of northern Honshu saw a slight uplift of only up to a few $\mathrm{cm}$, the dominant displacement in the eastern half of Honshu is a subsidence with a maximum of about
$50 \mathrm{~cm}$ on the Tohoku shore. The latter, in fact, exacerbated the tsunami damage along the shore, including the flooding of the Fukushima nuclear power plants.

\subsection{Pre-seismic/Foreshock deformation field of March 7-10}

We conduct a similar EOF analysis just for the preseismic period of the four days of March 7-10 which registered two major foreshocks on March 9. Figure 3 shows the leading EOF mode solutions elucidating the earthquakerelated signals in this pre-seismic period; their overall percentage variances are not high. The second foreshock (event \#2), of $M 6$, leaves no discernible signal. The first foreshock (event \#1), of $M 7.3$, did produce a minor displacement in the horizontal components, again in the east- 


\section{1st mode}

\section{East}

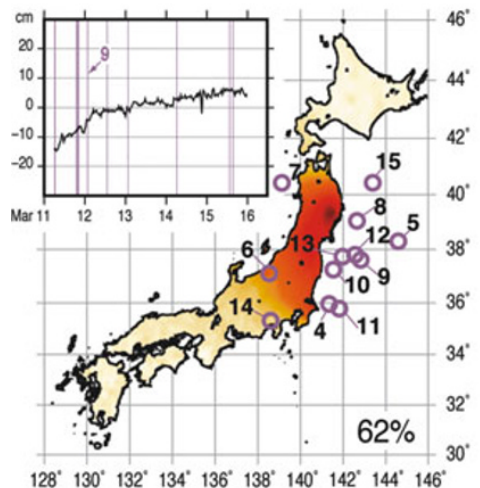

$128^{\circ} 130^{\circ} 132^{\circ} 134^{\circ} 136^{\circ} 138^{\circ} 140^{\circ} 142^{\circ} 144^{\circ} 146^{\circ}$

\section{North}

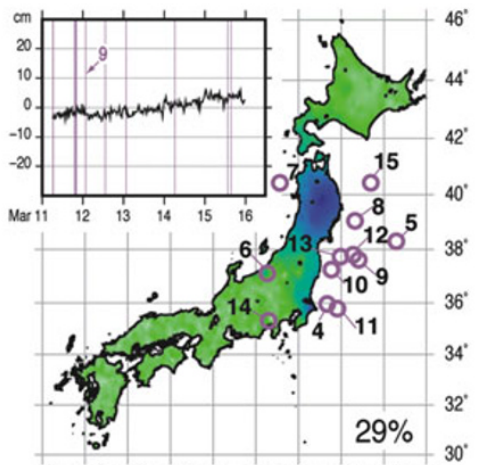

$128^{\circ} 130^{\circ} 132^{\circ} 134^{\circ} 136^{\circ} 138^{\circ} 140^{\circ} 142^{\circ} 144^{\circ} 146^{\circ}$

\section{2nd mode}

North
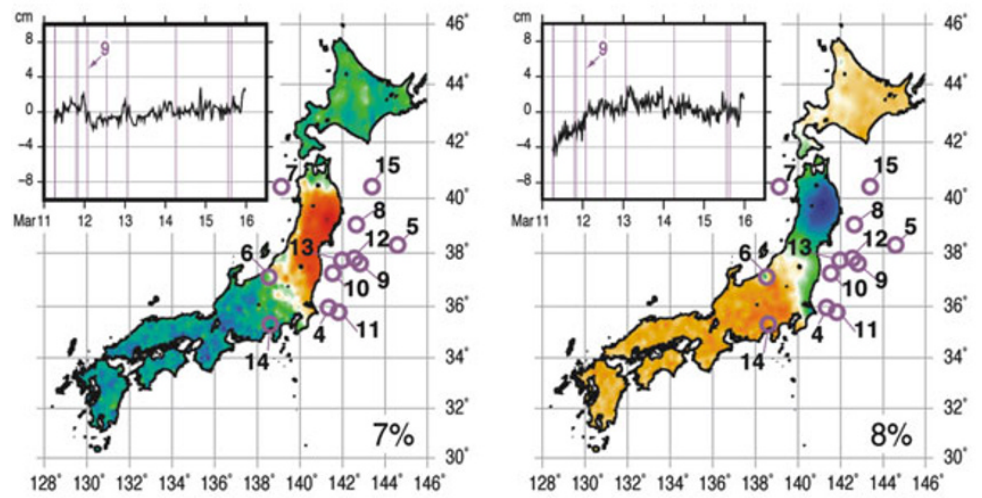

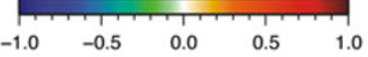

Up

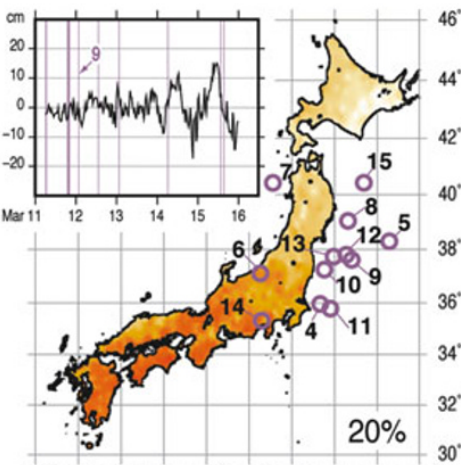

$128^{\circ} 130^{\circ} 132^{\circ} 134^{\circ} 136^{\circ} 138^{\circ} 140^{\circ} 142^{*} 144^{\circ} 146^{\circ}$

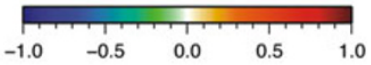

Up

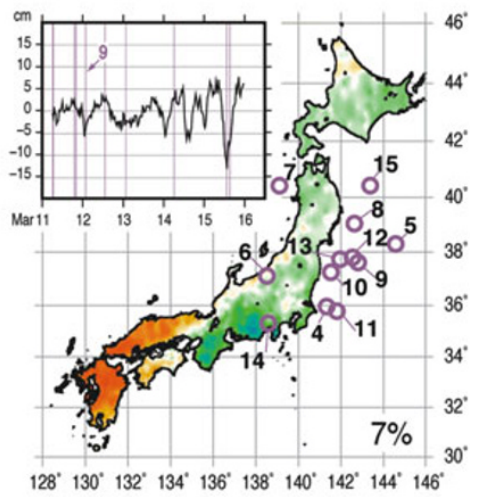

Fig. 4. Same as Fig. 2, but for EOF solutions for the post-seismic/aftershock period of 4.75 days, 14 min after the mainshock through March 15 . Upper and lower panels are the first and second EOF mode solutions, respectively. Origin time of the $M 6.5$ event \#9 is specifically indicated in the time series.

southeast direction, of a maximum of about $5 \mathrm{~cm}$ but too small a vertical signal to stand out in the presence of certain presumably non-seismic, unison undulations, all consistent with the relative amplitudes of the mainshock. Note that, instead of a post-seismic relaxation, an apparent reversal in the ground motion is evident in the eastward EOF time series after event \#1. We have carried out the same EOF analysis but limited to the local area (as opposed to the whole-Japan area): the results are basically the same.

\subsection{Post-seismic/Aftershock deformation field of March 11-15}

Figure 4 shows the first and second EOF mode solutions for the 4.75 days beginning nominally at 14 min after the mainshock. In the presence of the aftershocks, the east-component shows very clearly a post-seismic relaxation continuing in the eastward direction, with the temporal growth following a quasi-logarithmic function gradually reaching a $20 \mathrm{~cm}$ maximum over the studied few days. Similarly, the north-component pattern continued a south- ward motion, but the growth amplitude is relatively small, with no more than $10 \mathrm{~cm}$ maximum during the studied period. Taken together, the entire Honshu underwent an eastsoutheast horizontal deformation that is the strongest at the eastern shore, just like the co-seismic behavior of the mainshock. We note that the overall post-seismic horizontal deformation of the mainshock, although much smaller in magnitude, is somewhat more extensive towards the far-field than that of the co-seismic case (cf. Fig. 4). This is consistent with the finding of Ozawa et al. (2011).

There is an apparent change in trend in the horizontal EOF time series right at the occurrence of event \#9. This interesting behavior is consistent with the fact that the $M 6.5$ event \#9, being normal-faulting (Fig. 1) according to the GCMT determination, has an opposite focal mechanism to the mainshock. Even the second EOF modes, catching only $7 \sim 8 \%$ of the variance, show indications of this interesting pattern. In addition, the second EOF modes, in contrast to the first modes, reveal a dipolar pattern for northern and 


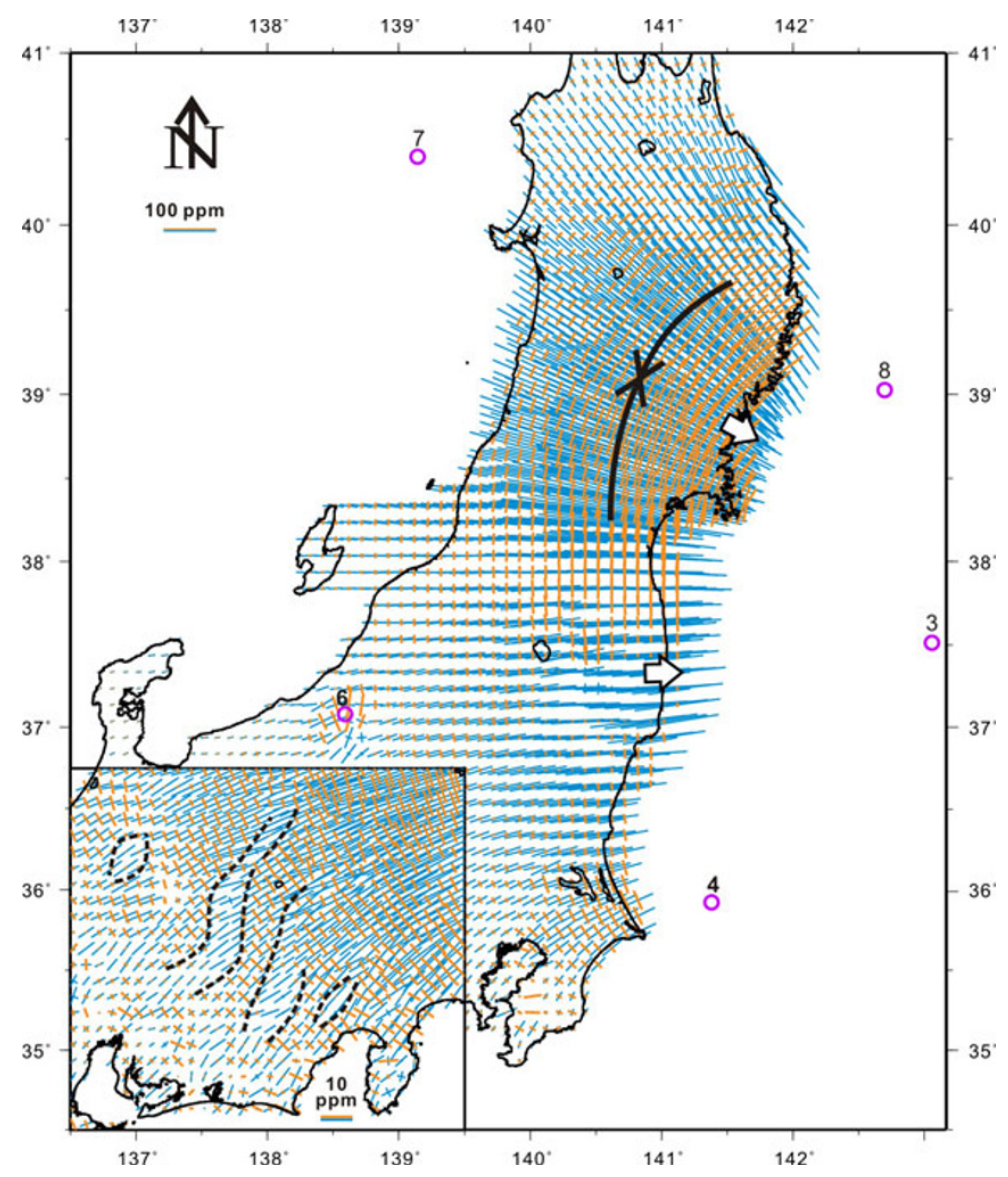

Fig. 5. The co-seismic horizontal strain field derived from the EOF mode for the deformation field solved using the 5-min of GEONET GPS data for March 11. The two perpendicular bars at each grid point indicate the principal axes where blue indicates dilatation and orange compression, and the bar length indicates the magnitude of the principal strain (note the enlarged scale for the lower left panel).

southern Honshu.

The vertical component of the leading EOF mode, on the other hand, contains no discernible mainshock-related post-seismic signal (beyond the first several hours, see Section 3.1) both in the first and second EOF mode solutions. Rather, the spatially quasi-unison and temporally undulating motions (Fig. 4) are reminiscent of the aforementioned CME. If not recognized, they may masquerade as vertical deformations with alternating signs depending on the timeframe in question (cf. Ozawa et al., 2011).

\subsection{Co-seismic strain field of March 11}

For the co-seismic deformation generated by the mainshock (aside from the small deformations by fore/aftershocks), the EOF solutions give the "before-andafter" temporal jump and associated spatial pattern. These can be readily converted by spatial differentiation into a significant, synoptic co-seismic horizontal strain field pattern, which is more conducive to geophysical interpretation. Here, we report the results using the high-rate 5-minute interval data during the 1-day period of March 11.

Thus, short of vertical gradient observations from the surface GPS, we compute the horizontal Cartesian gradients of the EW and NS deformation fields which were linearly interpolated into $0.1^{\circ} \times 0.1^{\circ}$ grids beforehand via the algorithm of Chang et al. (2003), thus forming the $2 \times 2$ (symmetric) strain-tensor matrix per unit block. The eigensolution of the matrix then gives the horizontal co-seismic principal strain at each grid node, shown in Fig. 5: the two perpendicular bars indicate its principal axes (according to the eigenvector) where blue indicates dilatation and orange compression, and the bar length (according to the eigenvalue) indicates the magnitude of the principal strain. The co-seismic strain field of northern to central Honshu is plotted under two panels with different scales for clarity. The maximum value of dilatation reaches 207 ppm and compression reaches $54 \mathrm{ppm}$ on the Tohoku shore, to be discussed below.

Assuming that the crust of northern Honshu is a Poisson solid of rigidity $2.9 \times 10^{11} \mathrm{dyn} / \mathrm{cm}^{2}$, as converted from the seismic velocity model (e.g. Zhao and Hasegawa, 1993; Sekiguchi, 2001), giving a bulk and Young's moduli of $6.3 \times 10^{11}$ and $7.2 \times 10^{11} \mathrm{dyn} / \mathrm{cm}^{2}$, respectively. The corresponding maximum compressional-stress drop of the northeast coast of Honshu then is estimated to be $3.9 \times 10^{6} \mathrm{~Pa}$, while the average compressional stress along the tangential arc indicated in Fig. 5 is approximately $2.8 \times 10^{6} \mathrm{~Pa}$.

\section{Discussions and Conclusions}

In this study, using GEONET GPS data we obtain the EOF modes of the 3-D surface deformation in Japan (onland) caused by the 2011 M 9.0 Earthquake off the Pacific coast of Tohoku, along with the major foreshocks and aftershocks. Situated on the west side of the presumably doublecouple seismic source along the off-shore NE-SW trending 
subduction zone, the islands of Japan experience essentially unilateral deformations. In particular, for northern Honshu where the dominant deformation occurred, the co-seismic displacement and the post-seismic relaxation were toward east-southeast with a maximum amplitude of nearly 4 meters. The vertical component experienced a subsidence of up to $50 \mathrm{~cm}$ on the east side toward the epicenter, but a slight uplift to the west.

The co-seismic strain field derived from the EOF solutions can provide further insights into a synoptic spatiotemporal scenario of surface deformation. Figure 5 shows such a strain field obtained for the day of March 11. Clearly emerging in northern Honshu is the pattern where the horizontal principal strains line up in such a way that the dilatation is largely radial, and the compression concentric, with respect to the epicenter of the $M 9.0$ mainshock, as if the northern Honshu region "slid", and sank when the vertical motion is considered, toward the epicenter, implying, in turn, a compression along the tangential direction of the arc as indicated. This behavior becomes stronger the closer it is to the epicenter. For central Honshu, the lower left portion of Fig. 5 shows, on the other hand, the NE-SW trending, banded pattern of alternating extension and compression in that direction (as emphasized by the dashed lines).

In addition, some major fore/aftershocks were found to have left distinct displacement signals in the EOF solutions. Figure 5 shows that the co-seismic-strain signals of two major aftershocks (both in central Honshu on March 11, which includes the aftershocks up to event \#8) were successfully captured in our EOF solutions. One is the large $M 7.9$ event \#4 just off-shore, and the other is the $M 6.3$ event \#6 on land. Both are characterized by a similar radialdilatation and concentric-compression pattern as the mainshock. Also, the first foreshock event \#1 of M 7.3 exhibits a post-seismic reversal of its co-seismic behavior particularly in the east-component. The $M 6.5$ event \#9, being normalfaulting, resulted in an apparent change in trend in the horizontal EOF time series opposite to that of the mainshock. The findings obtained in this study, not only regarding the mainshock but also for the whole sequence of fore- and aftershocks, can serve as useful constraints toward a better understanding of the physics of the seismo-genesis and the complex seismo-tectonic dynamics of the region.

Acknowledgments. The preliminary GPS time series were provided by the ARIA team at JPL and Caltech. All original GEONET RINEX data were provided to Caltech by the Geospatial Information Authority (GSI) of Japan. We thank Drs. L. C. Kuo, L. G. Yuan, S. Lallemand, and J. LaBrecque for discussions. This work is supported by the National Science Council of Taiwan under grants \# 100-3113-M-002-002, 98-2116-M-001-015 and 962116-M-002-012.

\section{References}

Ando, M., Source mechanisms and tectonic significance of historical earthquakes along the Nankai Through, Japan, Tectonophysics, 27, 119-140, 1975

Aoki, Y. and C. H. Scholz, Vertical deformation of the Japanese islands, 1996-1999, J. Geophys. Res., 108(B5), 2257, doi:10.1029/ 2002JB002129, 2003.

Bird, P., An updated digital model of plate boundaries, Geochem. Geophys. Geosyst., 4(3), 1027, doi:10.1029/2001GC000252, 2003.

Chang, C.-P., E. T. Y. Chang, J. Angelier, H. Kao, J.-C. Lee, and S.-B. Yu, Stress and strain field in Taiwan oblique convergent system: constrains from GPS observations and tectonic data, Earth Planet. Sci. Lett., 214, 115-127, 2003.

DeMets, C., A test of present-day plate geometries for northeast Asia and Japan, J. Geophys. Res., 97(B12), 17,627-17,635, 1992.

Dong, D., P. Fang, Y. Bock, F. Webb, L. Prawirodirdjo, S. Kedar, and P. Jamason, Spatiotemporal filtering using principal component analysis and Karhunen-Loeve expansion approaches for regional GPS network analysis, J. Geophys. Res., 111, B03405, doi:10.1029/2005JB003806, 2006.

Jolliffe, I. T., Principal Component Analysis, second edition, New York: Springer Verlag, Inc., New York, 2002.

Ozawa, S., T. Nishimura, H. Suito, T. Kobayashi, M. Tobita, and T. Imakiire, Coseismic and postseismic slip of the 2011 magnitude-9 TohokuOki earthquake, Nature, doi:10.1038/nature10227, 2011.

Preisendorfer, R. W., Principal Component Analysis in Meteorology and Oceanography, Elsevier, 1988.

Sagiya, T., S. Miyazaki, and T. Tada, Continuous GPS array and presentday crustal deformation of Japan, Pure Appl. Geophys., 157, 2,3032,322, 2000 .

Sagiya, T., A decade of GEONET: 1994-2003: The continuous GPS observation in Japan and its impact on earthquake studies, Earth Planets Space, 56(8), xxix-xli, 2004.

Sekiguchi, S., A new configuration and an aseismic slab of the descending Philippine sea plate revealed by seismic tomography, Tectonophysics, 341, 19-32, 2001.

Seno, T. and T. Takano, Seismotectonics at the trench-trench-trench triple junction off central Honshu, Pure Appl. Geophys., 129(1-2), 27-40, 1989.

Seno, T., S. Stein, and A. E. Gripp, A model for the motion of the Philippine Sea Plate consistent with NUVEL-1 and geologic data, J. Geophys Res., 98(B10), 17,941-17,948, 1993.

Seno, T., T. Sakurai, and S. Stein, Can the Okhotsk plate be discriminated from the North American plate? J. Geophys. Res., 101(B5), 11,305$11,315,1996$

Williams, S. D. P., Y. Bock, P. Fang, P. Jamason, R. M. Nikolaidis, L. Prawirodirdjo, M. Miller, and D. J. Johnson, Error analysis of continuous GPS position time series, J. Geophys. Res., 109, B03412, 1-19, 2004.

Zhao, D. and A. Hasegawa, P wave tomographic imaging of the crust and upper mantle beneath the Japan Islands, J. Geophys. Res., 98, 4,3334,353, 1993.

E. T. Y. Chang (e-mail: etychang@ntu.edu.tw) and B. F. Chao 